\title{
12 \\ VALUE ADDING MANAGEMENT OF BUILDINGS, WORKPLACES, FACILITIES AND SERVICES
}

\author{
Theo J.M. van der Voordt ${ }^{\star}$ and Per Anker Jensen
}

\section{Background}

In 2009, the second author of this chapter started a EuroFM workgroup with the aim to bring together researchers from different research environments, which were engaged or interested in comparing and developing joint research activities on the added value of facilities management (FM). Around the same time, he had developed a FM Value Map (Jensen, 2010, 2012). This input-throughput-output-outcome process model was inspired from the cause-effect principles of Strategic Mapping from Balanced Scorecard methodology by Kaplan and Norton (2000). It makes a distinction in six core business values and four values that are connected to the surroundings, and four main stakeholders (owners, staff, customers and society).

The first author of this chapter joined the EuroFM work group and added insights from the field of corporate real estate management (CREM). Important ideas were traced from the work by Nourse and Roulac (1993), who linked corporate strategy with eight corporate real estate strategies and fourteen real estate operating decisions, and by Lindholm et al. (2006), who linked similar real estate strategies to revenue growth, productivity growth and shareholder value, and various $\mathrm{PhD}$ projects.

The findings of the EuroFM work group have been published in the book The Added Value of Facilities Management: Concepts, Findings and Perspectives edited by Jensen et al. (2012a). This book presents academic research of twenty-two co-authors from seven nationalities on added value and Value Adding Management of buildings, workplaces, facilities and services.

In 2012, Jensen et al. (2012b) explored relevant research topics and findings on the added value of FM within research on FM, CREM and B2B marketing. Based on a brainstorming session with participants of the EuroFM work group, it was decided to invite experts to elaborate twelve value dimensions regarding state-of-the-art knowledge, how to manage and measure these value parameters, and future perspectives. At the European Facility Management Conference EFMC, 2013, Jensen, van der Voordt and Coenen organised a workshop about how to manage and measure different value dimensions. The attendants showed to interpret added value in different ways and to find it difficult to operationalise added value in clear parameters,

^ corresponding author: theovandervoordt@gmail.com 
interventions and ways to measure. Jensen et al. (2013) further explored similarities and dissimilarities in conceptual frameworks on the added value of FM and CREM and related stakeholders. Interviews with practitioners investigated if/how they apply the added value concept in practice, what values are prioritised, what interventions are implemented and how the outcomes are measured (van der Voordt \& Jensen, 2014). This confirmed the need for a coherent definition of added value and appropriate tools to measure different value parameters. A critical review of twenty-one papers from EFMC 2013, EFMC 2014 and CIB 2014 on the added value of FM and CREM showed a lack of integrated analyses of the added value, including sacrifices (time, money, risks), and which stakeholders benefit the most and the least from particular interventions (Jensen \& van der Voordt, 2015).

All these activities contributed to a second book, Facilities Management and Corporate Real Estate Management as Value Drivers: How to Manage and Measure Adding Value, edited by Jensen and van der Voordt (2017). This book tried to open the black box of input $\rightarrow$ throughput $\rightarrow$ output $\rightarrow$ outcome $\rightarrow$ impact/added value by discussing a taxonomy of six types of interventions, twelve value parameters, state-of-the-art of concepts and research findings for each value parameter, and ways to manage and measure added value.

The leading idea behind this research is that appropriate buildings, workplaces, facilities and services can add value to organisations, individuals and the society as a whole. Next, some main findings are summarised.

\subsection{Value, added value, value types and parameters}

The concept of value has been used for a long time. For instance, the economic theory of exchange value, going back to Rubin (1927), attempts to explain the exchange value or price of value or price of goods and services. Key questions include why goods and services are priced as they are, how the value of goods and services comes about and - for normative value theories how to calculate the correct price of goods and services. Economy, efficiency and effectiveness may be used to contribute to an assessment of the value for money provided by a purchase, project or activity. Economy refers to minimising the cost of resources used or required (inputs) spending less. Efficiency regards the relationship between the output from goods or services and the resources to produce them - spending well. Effectiveness regards the relationship between the intended and actual results of public spending (outcomes) - spending wisely (National Audit Office, 2020). The subjective theory of value believes that a good's value depends on the consumer's wants and needs (Stigler, 1950). In connection to supportive functions such as FM and CREM, Michael Porter discussed the concept of value chains and showed how primary and supportive business activities can contribute to more customers, financial profit and competitive advantage (Porter, 1985, 2001).

From an economic point of view, added value is created when financial value is added, i.e. lower costs and/or higher revenue for the organisation. However, Coenen et al. (2013) argue that value should be regarded as the cornerstone of FM, because its activities are used as inputs into the client's resource-integrating and value-creating activities as described in the value chain of Porter (1985), where FM is part of the organisations' infrastructure. They plea for including both the supply-side and demand-side perspective and identifying a wider scope of value exchange/creation from the point of view of different stakeholders. In line with this, added value may be defined as the trade-off between the benefits of one choice compared to another choice or an intervention in a current situation, and the sacrifices in terms of costs and risks to achieve these benefits, from the perspective of all stakeholders (Jensen et al., 2012a). 
In the book chapters by authors from different countries, disciplines and sectors (offices, universities, health care and industry), Jensen et al. (2012a) detected fifty different definitions of added value. They clustered these in six main different types of added value:

1 Use value: quality in relation to the needs and preferences of the end users;

2 Customer value: trade-off between benefits and costs for the customers or consumers;

3 Economic, financial or exchange value: the economic trade-off between costs and benefits;

4 Social value: connecting people by supporting social interaction, identity and civic pride;

5 Environmental value: environmental impact of FM, Green FM;

6 Relationship value: for example, getting high-quality services or experiencing a special treatment.

Other researchers clustered different types of value as well, for instance, in productivity, profitability and competitive advantage (De Vries et al., 2008) and ditto plus sustainability (Den Heijer, 2012). Later on, Jensen and van der Voordt (2017) clustered twelve value parameters into four categories: (1) people-related values (satisfaction, image, culture, health and safety); (2) process and product (productivity, adaptability, innovation and creativity, risk); (3) economy (cost, value of assets) and (4) societal (sustainability, corporate social responsibility). Interviews with practitioners showed that the values that are included in Value Adding Management practices depend on the vision, mission and objectives of the company, its life cycle, organisational culture (e.g. hierarchical versus a network organisation), commercial versus not-for-profit, branch (offices, healthcare, learning environments, retail and leisure), and contextual factors such as the labour market and economics (van der Voordt \& Jensen, 2014).

\subsection{Value Adding Management (VAM)}

Value Adding Management and related terms are widely used in the business and management literature. In the literature related to manufacturing, Value Adding Management is often used in a similar way as Lean Management with a focus on eliminating non-value-adding or 'waste' activities. In FM- and CREM-related literature, the focus is more often on the benefits part (Jensen \& van der Voordt, 2015).

In order to support decision makers in value adding FM and CREM, Hoendervanger et al. (2017) developed a Value Adding Management process model with four steps; see Figure 12.1 (for a summary, see van der Voordt et al., 2016). This model is action oriented and follows the same steps in the renowned Deming cycle (Gidey et al., 2014). The PDCA cycle is widely applied to support total quality management, which is familiar to many practitioners. The VAM model corresponds with the principles of Benefits Realization Management (BRM), a set of organisational change processes structured to close the gap between strategy planning and execution by ensuring the implementation of the most valuable initiatives (Serra \& Kunc, 2015). It also corresponds with the so-called Logic Model, which was developed in the early 1970s as a tool to evaluate the effectiveness of a program (Weiss, 1972; McCawley, no year; Millar et al., 2001). Common components are:

- Inputs: resources such as money, staff, equipment;

- Throughput/activities, e.g. the development of procedures or training programs;

- Outputs: what is produced, for instance, documents or the number of people that were trained;

- Outcomes/impacts: the changes or benefits that result from the intervention or program, e.g. increased skills of knowledge. 


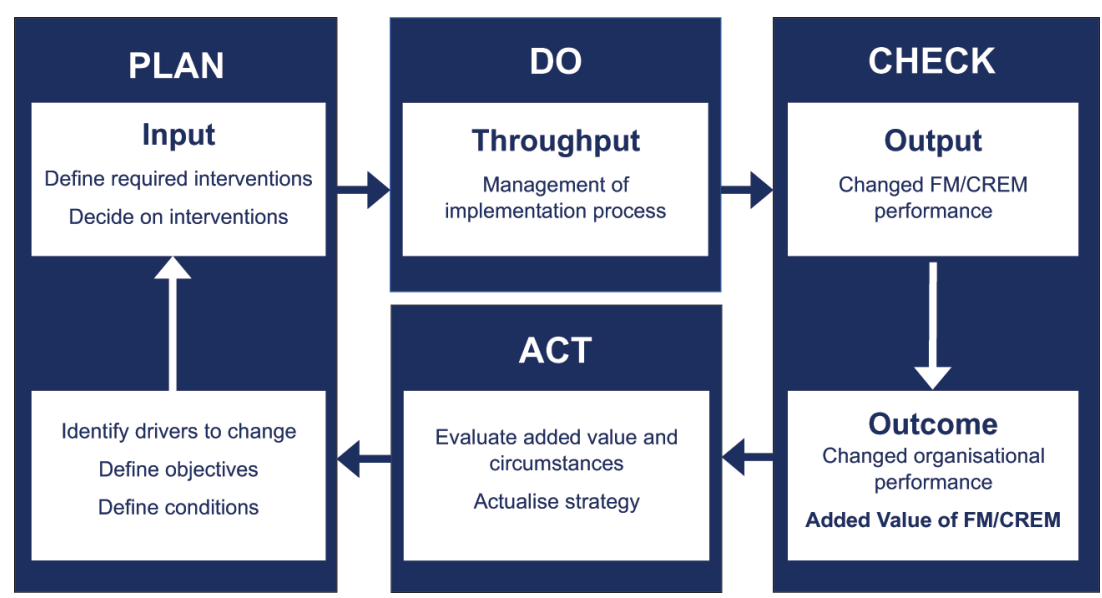

Figure 12.1 Value Adding Management model (Hoendervanger, Bergsma, van der Voordt, \& Jensen, In Jensen and van der Voordt (2017, chapter 17 on tools to manage and measure adding value by FM and CREM)

The principles of input-throughput-output-outcome/added value correspond with what to do and why, how to implement and how to measure its impact. However, what is missing in most organisational change frameworks is a clear link with FM and CREM, which is key in the VAM model presented in Figure 12.1.

The main actions in the Plan phase are to identify the drivers to change, i.e. to define if there is a gap between the desired and actual performance of the organisation and the accommodation, facilities and services, and to define which interventions may result in improved performance. The Plan phase ends with clear decisions about which interventions should be implemented and how to implement them. In order to support this first step, Jensen and van der Voordt (2020) developed a typology of Value Adding FM/CREM interventions. Analysing the context of Value Adding Management may start with exploring the different roles, interests and power of stakeholders involved, using stakeholder analysis. A SWOT analysis can help to identify the need and direction for change, concerning both the organisation and the FM/CREM processes and products.

The Do phase encompasses the implementation of the proposed interventions and management of the change process. Decisions to be made include who should be involved in the process and how, time schedules, how to cope with resistance to change and how to cope with the different needs of different stakeholders. A major challenge is to keep focus on the initial goals regarding adding specific values. Implementation processes tend to develop their own dynamics, which can easily shift the focus from long-term strategic organisational goals to short-term tactical and operational goals of the participants. A tailor-made approach should be designed that fits with the characteristics of the intervention (complexity, budget, risks, timeframe), the goals and the social/organisational context.

In the Check phase, the costs and benefits of the intervention(s) and its impact on the performance of the organisation and its facilities have to be measured, both during the change and ex-post, after the implementation of the intervention(s) has been realised. To be able to measure whether the performance has been improved, a baseline measurement i.e. an ex-ante measurement before the intervention is implemented is needed as well. It is also necessary to evaluate if the changed performance fits with the organisational strategy, mission, vision and objectives and as such adds value to the organisation. 
The Act phase is quite similar to the Plan phase. However, whereas the Plan phase may start with an analysis of changing internal or external circumstances or a strategic analysis of the strengths and weaknesses of the organisation and FM/CREM products and processes, these factors are already taken into account in the Act phase. When all objectives have been attained and maximum value has been added, the Act phase may be limited to consolidation of the new situation, until new drivers to change come to the fore. If the objectives are not sufficiently attained or not optimally, or if too many negative side effects come to the fore, new interventions or broadening or strengthening of earlier interventions should be considered. Another option is to reconsider the objectives. It may happen that the aimed performance was not realistic and feasible within the current conditions. Moreover, the context or conditions of the original objectives may have changed, which might force the organisation to change its organisational and/or FM/CREM strategy. If new or revised interventions have to be implemented, the Plan and Do phases start again.

The cyclic character emphasises that Value Adding Management is or should be a continuous process. Evaluation of realised output/outcome/added value may be a starting point for new interventions.

\subsection{Performance measurement}

In order to identify whether FM and CREM interventions add value to the organisation, its users and society as a whole, performance measurement before and after the intervention(s) is key, both of organisational performance and FM/CREM performance. Various models and tools are available about performance measurement (Riratanaphong et al., 2012). Table 12.1 presents a selection of possible FM and CREM interventions and tools to measure the output and outcomes, based on literature search and expert views (Jensen \& van der Voordt, 2017; van der Voordt \& Jensen, 2018). Various measuring tools can be combined in a Post-Occupancy Evaluation (POE), also called evaluation of buildings-in-use.

Which KPIs are or should be prioritised depends on the context and criteria such as tangibility, reliability, responsiveness, assurance (competence, courtesy, credibility, security) and empathy (access, communication, understanding the customer) (Shanin \& Mahbod, 2007).

\section{Applicability to workplace studies}

VAM theory has proven its value in various research projects. For instance, Petrulaitiene and Jylhä (2015) used semi-structured interviews to analyse six Finnish organisations on expected and perceived value of workplace concepts. The actual perceived value of the workplace concepts showed to be richer than the expected value in advance of workplace change. Besides, a shift from cost- to business-workplace strategies was noticed. Main tools to add value were active employee involvement and orientation towards their needs, activity-based offices with unassigned workspaces, and more meeting areas. One of the organisations expected reduced workplace costs and improved business processes. However, after applying a new activity-based workplace concept, hub creation, implementing virtual communication tools in meeting rooms and providing multi-purpose office space, it was found that added value was reached in all categories, with great improvements in process development and space itself. In another case, it was seen that a customer-driven approach also improved the performance in the People category such as the overall effectiveness, motivation, communication and flexibility of employees. Orientation towards employees' needs improved employee motivation through communication strategies and changing management style. This led to better customer services and improved the organisation's image and reputation. 


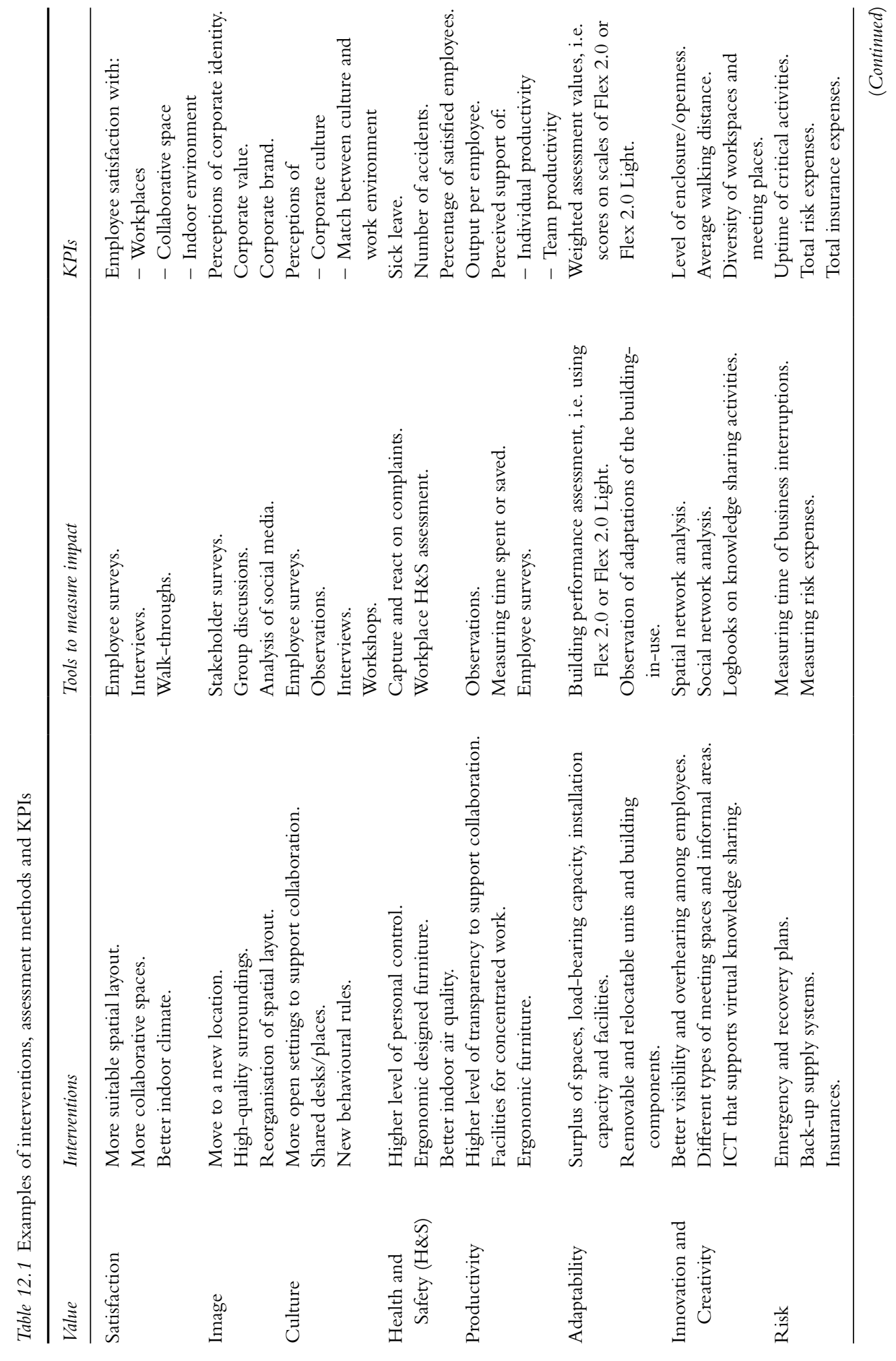


Theo J.M. van der Voordt and Per Anker Jensen

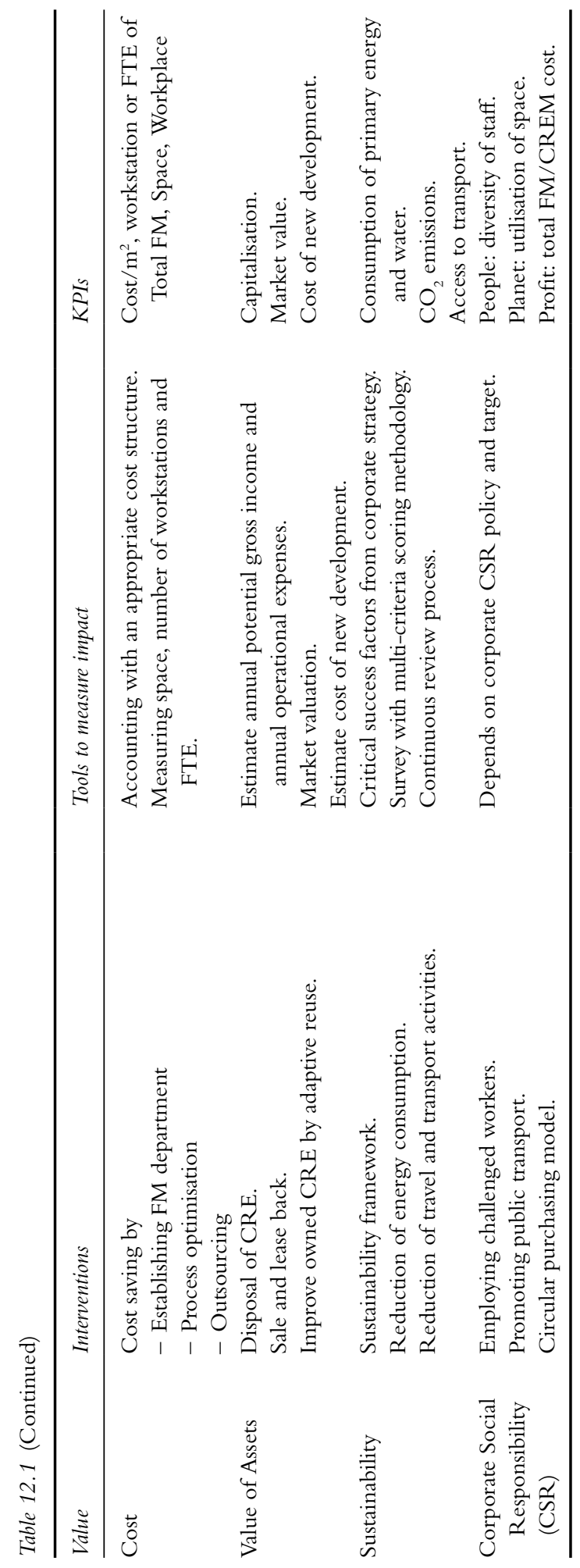


Using a quantitative national online survey with responses of more than 7,500 alumni from universities of applied sciences, Von Felten et al. (2015) analysed the potential demand gap in FM. Besides, they assessed whether FM has the potential to be a value driver in the core business, i.e. whether a company that invests less than one Euro into Facility Management services can increase its productivity by more than one Euro. The use value was measured by the potential of enhanced working productivity, which was compared with the potential enhanced FM resources (exchange value) to deliver the best quality of FM service. The study showed that more than three out of four respondents thought that the quality of their work would be slightly better, better or much better when a workplace without disturbance and appropriate ICT services are offered in the best possible way. Appropriate meeting points, technical installations, office services and catering were mentioned by over $50 \%$ of all respondents. The estimated annual perceived productivity gains by a workplace without disturbance and optimal ICT services were 50 hours and 31 hours respectively. With an average productivity potential per year of $€ 3,300$, the availability of 'Workplace without disturbance' was rated as having the greatest potential, followed by $€ 2,000$ for providing or enhancing 'ICT Hardware' and $€ 1,900$ for 'ICT Services'. Cost calculations showed that the benefits of increased productivity due to reduced disturbance by increasing the distance between workers and acoustical measures offset the estimated extra costs and resulted in a net financial added value of $€ 3,100$ per workplace per year.

Several studies assessed the added value of facilities and services such as adjustable workstations (sit-stand desks) in relation to health and wellbeing. For instance, Garland et al. (2018) conducted a quantitative study of an organisation in the USA with a group of staff getting adjustable workstations and a control group with traditional workstations. Participants received workplace wellness and ergonomic training, completed self-administered questionnaires and responded to repeated micro-polling four times over one year. Among participants with adjustable workstations, $47 \%$ reported decline in upper back, shoulder and neck discomfort; 88\% reported convenience to use, $65 \%$ reported increased productivity and $65 \%$ reported positive impact outside the workplace. The main sacrifices would be the cost of replacing traditional workstations with adjustable workstations and the cost of workplace wellness and ergonomic training.

\section{Methodology/research approach}

A combination of qualitative research methods such as content analysis of documents, workshops and different types of interviews (Waldburger \& Nielsen, 2012), and quantitative methods such as questionnaire surveys, real-time data collection using smart devices, and benchmarking of costs and benefits of different interventions may help to capture a holistic view of value adding workplace management. The former section discussed research projects using semistructured interviews (Petrulaitiene \& Jylhä, 2015) and quantitative surveys (Von Felten et al., 2015; Garland et al., 2018), whereas Section 5 will present some research projects using cards with the names of different values on it, asking the respondents whether they incorporate these values in daily practice, why and how (van der Zwart et al., 2012), and the combined use of document analysis and semi-structured interviews (Beckers et al., 2015). Based on a critical review of twenty-one research papers, Jensen and van der Voordt (2015) concluded that the use of mixed research methods is most appropriate, where quantitative results provide overview and identify the most important aspects; while qualitative research identifies specific interventions that can actually add value. 
In spite of the available body of knowledge, many questions still have to be answered for a further and deeper understanding of value adding workplace management (Jensen et al., 2012a), in particular:

- What are the key value drivers in workplace management, and which internal and external factors are leading?

- How does value adding workplace management vary by sector (offices, learning environments, health care facilities, retail and leisure)?

- Is it possible to further harmonise and standardise input factors (objectives, interventions), throughput (change management), output (workplace change), outcome (added value) and ways to measure (KPIs)?

- How can the theory be elaborated in practical guidelines and tools?

- How can the theory be applied in integrated business cases that weigh all value parameters and the different needs and interests of all stakeholders?

\section{Limitations}

Although the VAM theory has been applied in workplace research using different research designs and methods, various questions remain to be answered (see Section 3). In particular, how to weigh the different values and the different needs, preferences and influences of many stakeholders is quite complex and needs more attention in connection to decision-making theory. Most values are not easy to measure in a quantitative way, which limits application in benchmarking research. Validated measuring scales are needed to link VAM to preference-based design and management of workplaces, buildings and CRE portfolios (Arkesteijn, 2019).

\section{Theory relevance to practice}

Riratanaphong and van der Voordt (2015) assessed the goals and objectives behind workplace change in practice and how different added values have been measured in two offices in Thailand and one office in the Netherlands. It was found that many performance criteria and KPIs from literature are used in practice. However, apart from the Balanced Scorecard, no performance measurement system from literature is literally applied. Regarding most issues, none of the organisations conducted a comparison of the impact of their real estate on organisational performance before and after the change. In one case only, both ex-ante and ex-post data were collected about the appraisal of change by the end users, with a focus on employee satisfaction and perceived productivity support by the work environment. Other research also shows that, so far, the VAM theory, including all twelve value parameters and all four steps, is not yet often applied in practice. Usually, a limited number of values is incorporated in VAM. In workplace management, in particular user satisfaction, productivity and cost reduction are often highly prioritised (van der Voordt \& Jensen, 2014).

van der Zwart et al. (2012) assessed if and how hospitals apply Value Adding Management by FM/CREM in daily practice. Building on organisational documents, interviews with CEOs, building project leaders and FM/CREM managers started with an open question, whether adding value was used as a strategic tool. Then, little cards with the names of the value parameters were presented with the request to rank them on level of importance and why particular values were prioritised. Staff and patient satisfaction, productivity and cost effectiveness appeared quite often in the top three of most important values, whereas sustainability was mainly an issue that was taken into account when payback times were limited to less than three years. Reasons for 
prioritisation included a sense of urgency, level of importance (dependent on the context, economic situations, involved stakeholders and opportunities or threats of existing buildings), and aiming to attain the best possible ratio between high benefits and low costs.

Beckers et al. (2015) applied the VAM theory on learning spaces in thirteen Dutch universities of applied sciences and compared the espoused CRE strategy (found in documents) with the in-use strategy (measured by observations and interviews). Furthermore, they assessed the alignment of the CRE strategy to the corporate strategy and the alignment of CRE operating decisions with CRE strategy. The research findings show several layers of how CRE managers aim to align CRE with corporate goals to add value to the organisation. It appears that the CRE strategies in use are more clearly aligned with the corporate strategies than with the espoused CRE strategies.

It is expected that since the VAM theory is well disseminated, Value Adding Management of buildings, workplaces, facilities and services will be more and more connected to general business management in order to align CREM/FM interventions to the organisational context and organisational objectives (see also Chapter 9 on alignment theory).

\section{Further reading}

Jensen, P. A., \& van der Voordt, T. (Eds.). (2017). Facilities Management and Corporate Real Estate Management as Value Drivers: How to Manage and Measure Adding Value. Oxfordshire, UK: Routledge.

Jensen, P. A., van der Voordt, T., \& Coenen, C. (Eds.). (2012). The Added Value of Facilities Management Concepts, Findings and Perspectives. Lynbgy, Denmark: Centre for Facilities Management - Realdania Research, DTU Management Engineering, and Polyteknisk Forlag.

\section{References}

Arkesteijn, M. (2019). Corporate Real Estate Alignment: A Preference-Based Design and Decision Approach (Doctoral dissertation). Delft, NL: Delft University of Technology.

Beckers, R., van der Voordt, T., \& Dewulf, G. (2015). Aligning corporate real estate with the corporate strategies of higher education institutions. Facilities, 33(13/14), 775-793. doi:10.1108/F-04-2014-0035

Coenen, C., Alexander, K., \& Kok, H. (2013). Facility management value dimensions from a demand perspective. Journal of Facilities Management, 11(4), 339-353. doi:10.1108/JFM-10-2012-0049

Den Heijer, A. (2012). Linking decisions and performance: Adding value theories applied to the university campus. In P. A. Jensen, T. van der Voordt \& C. Coenen (Eds.), The Added Value of Facilities Management - Concepts, Findings and Perspectives. Lynbgy, Denmark: Centre for Facilities Management Realdania Research, DTU Management Engineering, and Polyteknisk Forlag.

De Vries, J., De Jonge, H., \& van der Voordt, D. J. M. (2008). Impact of real estate interventions on organizational performance. Journal of Corporate Real Estate, 10(3), 208-223. doi:10.1108/14630010810922094

Garland, E., Watts, A., Doucette, J., Foley, M., Senerat, A., \& Sanchez, S. (2018). Stand up to work: Assessing the health impact of adjustable workstations. International Journal of Workplace Health Management, 11(2), 85-95. doi:10.1108/IJWHM-10-2017-0078

Gidey, E., Jilcha, K., Beshah, B., \& Kitaw, D. (2014). The plan-do-check-act cycle of value addition. Industrial Engineering \& Management, 3(1), 100-124. doi:10.4172/2169-0316.1000124

Hoendervanger, J. G., Bergsma, F., van der Voordt, T., \& Jensen, P. A. (2017). Tools to manage and measure adding value by FM and CREM. In P. A. Jensen \& T. van der Voordt (Eds.), Facilities Management and Corporate Real Estate Management as Value Drivers: How to Manage and Measure Adding Value (pp. 199-222). Oxfordshire, UK: Routledge.

Jensen, P. A. (2010). The facilities management value map: A conceptual framework. Facilities, 28(3/4), 175-188. doi:10.1108/02632771011023131

Jensen, P. A. (2012). The making of the FM value map. In P. A. Jensen, T. van der Voordt \& C. Coenen (Eds.), The Added Value of Facilities Management - Concepts, Findings and Perspectives (pp. 44-55). Lynbgy, Denmark: Centre for Facilities Management - Realdania Research, DTU Management Engineering, and Polyteknisk Forlag. 
Jensen, P. A., Sarasoja, A. L., van der Voordt, T., \& Coenen, C. (2013). How Can Facilities Management Add Value to Organisations as Well as to Society? CIB World Building Congress, 5-9 May 2013, Brisbane, Australia.

Jensen, P. A., \& van der Voordt, T. (2015). The Added Value of FM: How Can FM Create Value to Organisations. A Critical Review of Papers from EuroFM Research Symposia 2013-2015. Baarn: EuroFM publication.

Jensen, P. A., \& van der Voordt, T. (Eds.). (2017). Facilities Management and Corporate Real Estate Management as Value Drivers: How to Manage and Measure Adding Value. Oxfordshire, UK: Routledge.

Jensen, P. A., \& van der Voordt, T. (2020). Typology of value adding FM/CREM interventions. Journal of Corporate Real Estate, 22(3), 197-214. doi:10.1108/JCRE-09-2019-0042

Jensen, P. A., van der Voordt, T., \& Coenen, C. (Eds.). (2012a). The Added Value of Facilities ManagementConcepts, Findings and Perspectives. Lynbgy, Denmark: Centre for Facilities Management - Realdania Research, DTU Management Engineering, and Polyteknisk Forlag.

Jensen, P. A., van der Voordt, Th., Coenen, C., von Felten, D., Lindholm, A., Balslev Nielsen, S., Riratanaphong, C., \& Schmid, M. (2012b). In search for the added value of FM: What we know and what we need to learn. Facilities, 30(6), 199-217. doi:10.1108/02632771211208486

Kaplan, R. S., \& Norton, D. P. (2000, September-October). Having trouble with your strategy? Then map it. Harvard Business Review, 78(5), 167-176.

Lindholm, A.-L., Gibler, K. M., \& Leväinen, K. T. (2006). Modelling the value adding attributes of real estate to the wealth maximization of the firm. Journal of Real Estate Research, 28(4), 443-475. doi:10. 1080/10835547.2006.12091187

McCawley, P. F. (no year). The Logic Model for Program Planning and Evaluation. Moscow, ID: University of Idaho.

Millar, A., Simeone, R. S., \& Carnevale, J. T. (2001). Logic models: A systems tool for performance management. Evaluation and Program Planning, 24, 73-81. doi:10.1016/S0149-7189(00)00048-3

National Audit Office. (2020). Assessing Value for Money. www.nao.org.uk/successful-commissioning/ general-principles/value-for-money/assessing-value-for-money/ (Accessed 11 August 2020).

Nourse, H. O., \& Roulac, S. E. (1993). Linking real estate decisions to corporate strategy. Journal of Real Estate Research, 8(4), 475-494. www.jstor.org/stable/44095474

Petrulaitiene, V., \& Jylhä, T. (2015). The perceived value of workplace concepts for organisations. Journal of Corporate Real Estate, 17(4), 260-281. doi:10.1108/JCRE-06-2015-0014

Porter, M. E. (1985). The Competitive Advantage: Creating and Sustaining Superior Performance. New York, NY: Free Press. Republished with a new introduction, 1998.

Porter, M. E. (2001). The Value Chain and Competitive Advantage. Understanding Business Processes. Oxfordshire, UK: Routledge.

Riratanaphong, C., \& van der Voordt, D. J. M. (2015). Measuring the added value of workplace change. Performance measurement in theory and practice. Facilities, 33(11/12), 773-792. doi:10.1108/F-122014-0095

Riratanaphong, C., van der Voordt, T., \& Sarasoja, A.-L. (2012). Performance measurement in the context of CREM and FM. In P. A. Jensen, T. van der Voordt \& C. Coenen (Eds.), The Added Value of Facilities Management - Concepts, Findings and Perspectives (pp. 123-145). Lynbgy, Denmark: Centre for Facilities Management - Realdania Research, DTU Management Engineering, and Polyteknisk Forlag.

Rubin, I. I. (1978). Abstract labour and value in Marx's system. Capital and Class, 5, 107-139. First published: Pod Znamenem Marksizma, 1927.

Serra, C. E. M., \& Kunc, M. (2015). Benefits realization management and its influence on project success and on the execution of business strategies. International Journal of Project Management, 33(1), 53-66. doi:10.1016/j.ijproman.2014.03.011

Shanin, A., \& Mahbod, M. A. (2007). Prioritization of key performance indicators. An integration of analytical hierarchy process and goal setting. International Journal of Productivity and Performance Management, 56(3), 226-240. doi:10.1108/17410400710731437

Stigler, G. J. (1950). The development of utility theory. Part I. Journal of Political Economy, 58(4), 307-327. www.jstor.org/stable/1828885

van der Voordt, T., \& Jensen, P. A. (2014). Adding Value by FM: Exploration of Management Practice in the Netherlands and Denmark. EFMC 2014, 4-6 June, Berlin.

van der Voordt, T., \& Jensen, P. A. (2018). Measurement and benchmarking of workplace performance: Key issues in value adding management. Journal of Corporate Real Estate, 20(3), 177-195. doi:10.1108/ JCRE-10-2017-0032 


\section{Value Adding Management}

van der Voordt, T., Jensen, P. A., Hoendervanger, J. G., \& Bergsma, F. (2016). Value adding management of buildings and facility services in four steps. Corporate Real Estate Journal, 6(1), 42-56. http://orbit. dtu.dk/files/128526837/CREJ_VAMmodel_final.pdf

van der Zwart, J., Prevosth, J., \& van der Voordt, T. (2012). Adding value by FM and CREM in Dutch hospitals. In P. A. Jensen, T. van der Voordt \& C. Coenen (Eds.), The Added Value of Facilities Management - Concepts, Findings and Perspectives (pp. 206-222). Lynbgy, Denmark: Centre for Facilities Management - Realdania Research, DTU Management Engineering, and Polyteknisk Forlag.

Von Felten, D., Böhm, M., \& Coenen, C. (2015). Multiplier Effects Through FM Services: A Survey-Based Analysis of Added Value in FM. 14th EuroFM Research Symposium, 1-3 June, Glasgow.

Waldburger, D., \& Nielsen, S. B. (2012). The added value of quantitative research approaches. In P. A. Jensen, T. van der Voordt \& C. Coenen (Eds.), The Added Value of Facilities Management-Concepts, Findings and Perspectives (pp. 146-161). Lynbgy, Denmark: Centre for Facilities Management - Realdania Research, DTU Management Engineering, and Polyteknisk Forlag.

Weiss, C. H. (1972). Evaluation Research. Methods for Assessing Program Effectiveness. New Jersey: PrenticeHall, Inc., Englewood Cliffs. 